\title{
A construção do Código Florestal Brasileiro e as diferentes perspectivas para a proteção das florestas
}

\section{The construction of the Brazilian Forest Code and the different perspectives for forest protection}

Pedro Augusto Costa Roriz - Mestre em Ciências de Florestas Tropicais pelo Instituto Nacional de Pesquisas da Amazônia; professor do Instituto Federal de Educação, Ciência e Tecnologia do Amazonas, Campus Humaitá-AM. E-mail: pedro.roriz@ifam.edu.br

Philip Martin Fearnside - Ph.D. em Ciências Biológicas pela University of Michigan; pesquisador e professor do curso de Pós-Graduação em Zoologia do Instituo Nacional de Pesquisas da Amazônia, Manais-AM. E-mail: pmfearn@inpa.gov.br

\section{Resumo}

OCódigo Florestal brasileiro surgitem 1934 e, por sua inaplicabilidade, foi atualizado em 1965 e vigorou durante quase 50 anos. O Código de 1965 não foi cumprido rigorosamente, sendo novamente alterado em 2012 com a justificativa de que impedia o desenvolvimento econômico. As alterações geraram críticas no meio científico, por fragilizar a proteção dos recursos naturais e beneficiar proprietários rurais que não cumpriam a lei, porém tiveram a aprovação dos setores ligados ao agronegócio. O objetivo deste trabalho é compreender a evolução da legislação florestal brasileira, os motivos que levaram à aprovação da Lei no 12.651, de 2012, e quais os argumentos contrários a essa norma. A partir da revisão bibliográfica realizada, conclui-se que as mudanças na legislação regularizam infrações e abrem caminho para o desenvolvimento econômico unilateral.

\section{Palavras-chave}

Legislação ambiental. Política florestal. Reserva legal. Área de Preservação Permanente.

\begin{abstract}
The Brazilian Forest Code was enacted in 1934 and, because of its inapplicability, it was updated in 1965 and remainedin force for almost 50 years. The 1965 Forest Code was not strictly enforced, and the Code was changed again in 2012 based on the justification that the previous version impeded economic development. The recent alterations generated criticism from the scientific community because the changes weaken protection of natural resources and benefit landowners who have not obeyed the law, but the alterations had approval of sectors related to agribusiness. The objective of the present study was to understand the evolution of Brazil's forest legislation, the reasons that led to adoption of law $n^{\circ} 12.651$ of 2012 , and the arguments against this law. From a literature review it is evident that the legislative change was intended to legalize violations and pave the way to unilateral economic development.
\end{abstract}

\section{Keywords}

Environmental law. Forest policy. Legal forest reserve. Permanent Preservation Area. 


\section{INTRODUÇÃO}

O Código Florestal Brasileiro foi criado em 1934, através do Decreto $\mathrm{n}^{\circ}$ 23.793, com o intuito de garantir a manutenção das florestas (AHRENS, 2005). Foi substituído em 1965 pelo “novo" Código Florestal (Lei n 4.771) que, apesar de sofrer diversas alterações por meio de medidas provisórias, vigorou por 47 anos.

Em 25 de maio de 2012 foi aprovada a Lei n 12.651, o "mais novo" Código Florestal Brasileiro, em substituição ao de 1965. Baseada em uma proposta normativa (Projeto de Lei n ${ }^{\circ}$ 1876/99) e criticada por diferentes instituições e pesquisadores (ANA, 2010; MPF, 2011; PIEDADE; GRAÇA, 2011a,b; SBPC; ABC, 2012), a nova legislação alterou as regras de proteção ambiental para as propriedades privadas e incorporou mecanismos que visam auxiliar a regularização fundiária.

Diferente das versões anteriores, o Código Florestal de 2012 surge explicitamente com base na premissa de assegurar o desenvolvimento econômico (REBELO, 2010) e de legalizar as irregularidades advindas do não cumprimento da lei anterior (SAUER; FRANÇA, 2012). Enquanto a lei de 1965 e as alterações posteriores (leis, medidas provisórias e resoluções do CONAMA) promoveram maiores restrições ao uso dos recursos florestais, a legislação atual flexibiliza a proteção ambiental e cria um novo paradigma de adequação da regra à realidade e não da realidade à regra.

Dentre os pontos mais polêmicos dessas alterações estão a definição e legitimação de áreas de preservação permanente e de reserva legal, dois instrumentos considerados essenciais à proteção das formações vegetais brasileiras (SPAROVEK et al., 2010). Ambas sofreram mudanças que reduzem as áreas protegidas e permitem o uso de maiores extensões pelo proprietário rural e pelo poder público em determinadas situações.

Essas características fazem do atual Código Florestal um instrumento controverso tanto do ponto de vista ambiental quanto da formulação da Lei, pois geram dúvidas sobre a fundamentação utilizada e as suas consequências, os impactos futuros e a eficácia na conservação das florestas.

Este trabalho consiste em uma revisão bibliográfica visando compreender a evolução do Código Florestal Brasileiro e as situações que culminaram nas alterações aprovadas em 2012, as bases científicas que pautam ou deveriam pautar suas diretrizes sobre a conservação das florestas, bem como entender as possíveis consequências da nova Lei. 


\section{O CÓDIGO FLORESTAL DE 1934: OS PRIMEIROS MECANISMOS LEGAIS DE PROTEÇÃO ÀS FLORESTAS}

O precursor do primeiro Código Florestal Brasileiro e a primeira legislação a tratar da proteção de florestas no país foi o Regimento sobre o pau-brasil de 1605 (SIQUEIRA; NOGUEIRA, 2004), que versava exclusivamente sobre a conservação desta espécie (Caesalpiniae chinata Lam.). Com o objetivo de controlar a extração e garantir a rentabilidade para a coroa Portuguesa, o regimento previa multas, exílio, açoites e até pena de morte para quem retirasse a dita madeira sem autorização ou além da cota estabelecida. Proibia ainda a abertura de roças em florestas de pau-brasil através de queimadas e recomendava que o corte fosse feito com prevenção de danos às raízes e brotações ${ }^{1}$. Dessa forma, deu-se início à legislação florestal no Brasil, com caráter estritamente econômico e visando a concentração de renda.

De fato, até a Constituição brasileira de 1934, cujo texto incluiu a obrigação do Estado de "proteger as belezas naturais", toda ação ambiental era de cunho econômico (MEDEIROS et al., 2004). Como exemplo, tem-se o primeiro Código Florestal implementado em território nacional. De caráter estadual e sob a Lei no 706, legislava sobre as florestas do estado do Paraná. Criava o conceito de florestas protetoras, aquelas responsáveis por proteger os recursos hídricos, encostas e o solo, mas destacava-se pela característica de tentar controlar o mercado e garantir a produção (CARVALHO, 2007). Incentivava o plantio de espécies exóticas e até mesmo oferecia prêmios em dinheiro ou propriedades àqueles que convertessem campos ou pastagens em florestas de produção (PARANÁ, 1907).

Já com a existência de grupos e entidades ligados ao meio ambiente (FRANCO; DRUMMOND, 2009) e no contexto de reestruturação da Constituição brasileira na década de 1930, foi criado o primeiro Código Florestal Brasileiro, juntamente com outras políticas nacionais relacionadas ao meio ambiente, como o Código de Mineração, Código de Caça e Pesca e o Código de Águas (MEDEIROS et al., 2004).

Todavia, acredita-se que ainda existiam interesses econômicos na criação de uma legislação de proteção às florestas, como garantir a manutenção do mercado madeireiro e evitar a "pilhagem" de recursos (TERRA DE DIREITOS, 2009). Mesmo assim, a primeira legislação trouxe conceitos importantes e as bases para alguns instrumentos criados posteriormente, como Reserva Legal e Área de Preservação Permanente (MEDEIROS et al., 2004).

\footnotetext{
Regimento do Pau-Brasil, 1605. Disponível em: <http://www.historiadobrasil.net/ documentos/pau_brasil.htm>. Acesso em: 5 jul. 2013.
} 
Dentre esses conceitos é possíveldestacar que as florestas eram consideradas bens de interesse comum à sociedade e o direito de propriedade privada era limitado em relação às formações vegetais naturais; que a reponsabilidade de conservação das florestas era comum às esferas pública e privada; e que havia proibição de desmate em mais de $3 / 4$ da propriedade (com ressalva às pequenas) (BRASIL, 1934).

Todas essas características remetem ao conceito atual de Reserva Legal. Já as definições de Área de Preservação Permanente (APA) e Unidade de Conservação (UC), podem ser associadas à divisão das florestas em duas das quatro categorias descritas na lei (ANDRADE; SILVA, 2003; BORGES et al., 2011). Respectivamente, relacionam-se às florestas protetoras aquelas com a função de proteção ambiental, como fixação de dunas, contenção de erosão, manutenção do regime hídrico e defesa de fronteiras; e as remanescentes sendo parques e regiões com espécies consideradas "preciosas". As outras duas categorias são as florestasmodelo, com plantios de espécies exóticas ou nativas; e as florestas de rendimento, aquelas que não se enquadram nas definições anteriores (BRASIL, 1934).

Vale destacar também que as florestas protetoras e remanescentes eram de proteção perene, e que era proibida a derrubada da vegetação em encostas de morros (BRASIL, 1934), duas atribuições que reforçam o caráter permanente e preservacionista para áreas frágeis, incorporado nas legislações posteriores através do conceito de Área de Preservação Permanente. Outro ponto previsto em relação à conservação era a proibição de queimadas sem autorização (BRASIL, 1934), demonstrando que essa preocupação já existia à época.

Ainda que apresentassem maior restrição ao corte, as florestas protetoras e remanescentes poderiam ser utilizadas em regime de exploração limitada, desde que não fossem caracterizadas como parques (BRASIL, 1934). Esta condição se assemelha aos dispositivos das leis posteriores, que permitem a utilização de forma sustentável da Reserva Legal.

No que tange ao caráter socioeconômico da legislação, havia previsão de indenização, no caso da propriedade que fosse considerada total ou parcialmente como floresta protetora. As florestas eram isentas de impostos adicionais, por sua existência na propriedade, e ainda aquelas definidas como protetoras também ficavam isentas dos impostos sobre a terra em que se situavam. De fato, concretizava-se um incentivo econômico à manutenção dessas florestas e criava-se uma ideia similar à das reservas particulares de patrimônio privado em que a manutenção da vegetação se dá por iniciativa voluntária e não compulsória (MEDEIROS et al., 2004). Da mesma forma que atualmente, tal incentivo ainda não se mostrava suficientemente atrativo para que se deixasse de produzir sobre a terra (BORGES et al., 2011). 
Portanto, o Código Florestal de 1934 pode ser considerado conservacionista (BORGES et al., 2011), já que incorporava os princípios de proteção não só das formações vegetais, como também dos recursos hídricos e áreas frágeis (RIBEIRO, 2011). Mantinha o interesse em garantir a prosperidade do mercado madeireiro e a segurança socioambiental, mas também previa a proteção pelo próprio valor de existência das espécies consideradas raras. Porém, pouco praticável àquela época, o Código foi substituído em 1965, em uma nova tentativa de evitar maiores perdas econômicas e ambientais (RIBEIRO, 2011).

\section{O CÓDIGO FLORESTAL DE 1965: ATUAL OU À FRENTE DO SEU TEMPO?}

Sintetizando com mais eficiência em 50 artigos os 110 do Código precedente (RIBEIRO, 2011), a Lei no 4.771 de 1965 instituiu o até então "novo" Código Florestal Brasileiro, já que o anterior tinha se mostrado ineficaz e obsoleto (BREDA et al., 2011). Criado sob a premissa da proteção ao meio ambiente (BORGES et al., 2011), só se tornou efetivo na década de 1990, devido à criação de normas correlatas (BENJAMIN, 2000; RIBEIRO, 2011) e ao crescente apelo ambiental.

De fato, a sua aprovação na década de 1960 parece surpreendente e atrelada à certeza da inaplicabilidade (BENJAMIN, 2000), já que a justificativa para a sua concepção é fortemente conservacionista, evidenciando as preocupações com a manutenção do ciclo hidrológico, o modo de produção que degrada o solo, enchentes anormais, processos de desertificação e a futura escassez dos recursos naturais (MONTEIRO FILHO, 1962). Havia o entendimento de que a proteção ambiental conduziria à manutenção das atividades agropecuárias e garantiria melhor produção (IGARI; PIVELLO, 2011).

Essa mesma justificativa poderia ser aplicada atualmente em qualquer discurso conservacionista, uma vez que muitas das temáticas abordadas seriam as mesmas. Poderiam até mesmo pautar uma alteração legislativa que pretendesse aumentar a proteção sobre os recursos naturais. Então, o Código Florestal de 1965, considerado inovador e revolucionário (BENJAMIN, 2000), propunha-se a lidar com dilemas ambientais futuros ou as questões existentes na década de 1960 continuam as mesmas? E se as questões ambientais continuam as mesmas, a lei foi ineficaz em solucioná-las ou mesmo minimizá-las?

Seguindo conceitos do seu predecessor, o Código Florestal de 1965 considerava as florestas bens de interesse comum e limitava o uso da propriedade rural, tornando-se assim importante um instrumento disciplinador da atividade florestal (BORGES et al., 2011). Definiu o conceito de “áreas de preservação 
permanente" (artigo $1^{\circ}$ ), determinando sua localização e tamanho (artigos $2^{\circ}$ e $3^{\circ}$ ), e também definiu o conceito de "reserva legal" (artigo $1^{\circ}$ ), com as porcentagens das áreas de vegetação a serem mantidas em cada região (artigo 16).

Enquanto as áreas de preservação permanente eram responsáveis pela conservação dos recursos hídricos, da paisagem, da estabilidade geológica, da biodiversidade, dos fluxos gênicos, do solo e do bem estar das populações humanas, a reserva legal era necessária ao uso sustentável dos recursos naturais, à conservação dos processos ecológicos, à conservação da biodiversidade e ao abrigo e proteção de espécies nativas da flora e da fauna (BRASIL, 1965). Havia dois instrumentos com funções diferentes e complementares: o primeiro visava proteger áreas frágeis; e o segundo conservar a existência das formações vegetais e garantir a manutenção dos processos ecológicos relacionados a elas em todo o território nacional. De forma mais ampla, a proteção das florestas poderia ser entendida como um meio para atingir como fins a conservação de solos, recursos hídricos e fauna (AHRENS, 2005).

Devido ao caráter conservacionista, e não preservacionista do Código, nas reservas legais era permitido o uso sustentável - característica que torna a legislação equilibrada entre econômico e o ambiental, por controlar o desmatamento sem inviabilizar o uso das florestas (SIQUEIRA; NOGUEIRA, 2004; BREDA et al., 2011).

Uma das alterações instituída pelo Código de 1965, em regime de medida provisória (MP no 1.511, de 1996), foi o aumento da reserva legal no bioma Amazônia, de 50\% para 80\%. Depois de 30 anos da sua promulgação, a legislação seguia ignorada tanto pelo poder público quanto pela comunidade científica, enquanto o desmatamento crescia, principalmente na Amazônia. Sobretudo com o aumento da reserva legal em 1996, o custo de oportunidade implícito no cumprimento do Código chegou a níveis extraordinariamente altos em áreas aptas para o plantio de soja, cujo valor estimado em Mato Grosso chegou a totalizar US\$3-5,6 bilhões (STICKLER et al., 2013). Isto fortaleceu o descumprimento da lei e, a partir do aumento de fiscalização em 2004, também fortaleceu a ação da bancada "ruralista" (deputados e senadores no Congresso Nacional representando grandes proprietários de terra) para diminuir ou eliminar as restrições (STICKLER et al., 2013).

Desde 1988, o desmatamento vem sendo monitorado anualmente (com a exceção de 1993) pelo programa PRODES, do Instituto Nacional de Pesquisas Espaciais (INPE). Cada vez que os resultados eram anunciados, e se indicavam um aumento substancial do desmatamento, o anúncio era acompanhado de um "pacote" de medidas ostensivas, tais como confisco de motosserras ou aumento 
das multas. A mudança do percentual da área de reserva legal foi anunciada com a liberação dos dados em 1996, que indicavam um aumento do desmatamento entre 1991 e 1994 (mas ainda não admitam o grande aumento do desmatamento ocorrido em 1995, em consequência do "Plano Real", pela implantação de medidas econômicas em 1994). A mudança da área de reserva legal visava evitar a pressão política e social, nacional e internacional (BENJAMIN, 2000; SIQUEIRA; NOGUEIRA, 2004). De fato, houve uma contenção e redução do desmatamento anos depois, mas devido principalmente a outros fatores (FEARNSIDE, 2006, 2008), não havendo indicações que o maior rigor da legislação tenha atingido o seu objetivo (ALMEIDA et al., 2013).

O que a lei ainda deixava indefinido em relação à reserva legal, era sua localização dentro da propriedade. Não havia especificação que garantisse a melhor distribuição quanto aos tipos de vegetação. A reserva legal era delimitada com interesses diversos, privilegiando a manutenção das formações vegetais em terrenos acidentados, de mais difícil mecanização e baixa aptidão agrícola (BONNET et al., 2006; DELALIBERA et al., 2008).

Outro aspecto importante da lei era diferenciar as responsabilidades dos grandes e pequenos proprietários (posse rural familiar) com relação ao uso da terra (TERRA DE DIREITOS, 2009). Aos pequenos produtores era permitido o uso sustentável das áreas de preservação permanente, a recomposição da reserva legal com o cultivo de espécies frutíferas ou ornamentais, mesmo que exóticas, e o cômputo das áreas de preservação permanente no total percentual da reserva legal (BRASIL, 1965).

Mesmo assim, o déficit de áreas de preservação permanente e reserva legal chegou a 85 milhões de hectares (SPAROVEK et al., 2011), demonstrando a ineficiência no cumprimento da lei. A morosidade da justiça, a falta de incentivo econômico, a corrupção, a pouca fiscalização, a fragilidade institucional e a própria cultura de infringir a legislação foram, ao longo dos anos, os maiores responsáveis pelo não cumprimento da lei (ELLINGER; BARRETO, 2011). Ainda assim, a junção de áreas de preservação permanente e de reserva legal abrange uma área mais extensa de vegetação sob proteção que as Unidades de Conservação (SPAROVEK et al., 2010), comprovando a importância das propriedades rurais na conservação da biodiversidade brasileira (MICHALSKI et al., 2010).

Afinal, a Lei 4.771, de 1965, foi de suma importância para a manutenção da integridade das formações vegetais no país, garantindo o controle legal sobre parte da vegetação em propriedades privadas e permitindo o desenvolvimento econômico de forma ambientalmente equilibrada. Não foi mais efetiva devido 
à visão equivocada de que a mudança na lei, e somente a lei, é capaz de mudar a realidade (BREDA et al., 2011).

Em uma nova tentativa de melhorar a proteção ambiental e dando suporte ao Código Florestal, em 1998 foi criada a "Lei de Crimes Ambientais" (Lei $n^{\circ}$ 9.605/98), que impunha sanções estritas que até então não eram aplicadas por serem baseadas em atos administrativos (HIRAKURI, 2003). A partir da possibilidade de punição mais rígida houve um desconforto por parte daqueles que estavam em desacordo com a lei, e em 1999 surgiu a primeira proposta efetiva (Projeto de Lei 1876/1999) para a alteração da Lei de Crimes Ambientais

e substituição do Código Florestal. À época, a substituição já era criticada por pesquisadores e juristas, que alegavam que o Código Florestal não necessitava de alterações e as propostas só serviriam para regularizar desmatamentos, ampliar a fronteira agrícola, "mutilar" os instrumentos legais e abrir brechas para permitir maior atividade econômica em áreas antes protegidas (BENJAMIN, 2000; FEARNSIDE, 2000).

O projeto de 1999 ficou "engavetado", até que, em 2008, outras duas novas medidas contribuíram para acelerar a reformulação do Código e trazer novamente as discussões à tona: a Resolução no 3545 do Banco Central, que previa o financiamento agropecuário na Amazônia mediante documentação de regularidade ambiental; e o Decreto $\mathrm{n}^{\circ}$ 6.514, que exigia a regulamentação da Reserva Legal e fazia valer a Lei de Crimes Ambientais, prevendo multa àqueles que não estivessem em acordo com a legislação na data da publicação do Decreto (22 de julho de 2008) (SAUER; FRANÇA, 2012).

Devido à dificuldade em se cumprir o prazo para a regularização da Reserva Legal, houve cinco prorrogações, sendo a última em junho de 2012 (Decreto 7.719/2012), ano em que foi aprovado o mais novo Código Florestal Brasileiro, que mudou, dentre outras regras, as que dispõem sobre as reservas legais e as áreas de preservação permanente.

\section{O CÓDIGO FLORESTAL DE 2012: AS MUDANÇAS APROVADAS}

Sob a premissa de que a lei florestal gerava entraves à produção agropecuária e prejudicava os pequenos produtores rurais (REBELO, 2010), o "novo" Código Florestal de 1965 foi alterado e substituído pela Lei no 12.651, de 2012. As principais mudanças nesse "mais novo" Código diziam respeito às definições de Reserva Legal, Área de Preservação Permanente, pequena propriedade rural, de utilidade pública e interesse social e a incorporação de dois instrumentos: o Cadastro Ambiental Rural e o Programa de Regularização Ambiental (BRASIL, 2012). 
A vegetação nas áreas de preservação permanente passou a ser computada para obtenção do percentual de reserva legal (artigo 15), que agora pode ser de $50 \%$ em municípios da Amazônia onde mais de 50\% de sua área ou mais de 65\% da área do estado estiverem sob o regime de Unidades de Conservação ou Terras Indígenas (artigo 12). A recomposição da reserva legal desmatada em data anterior a julho de 2008 podia ser realizada em nível de bioma ou dentro da propriedade, com a utilização de espécies exóticas que tenham o seu uso econômico futuro assegurado (artigo 66). Já os imóveis rurais com até quatro módulos fiscais ficam isentos da recomposição, desde que os desmatamentos sejam anteriores a julho de 2008 (artigo 67).

As Áreas de Preservação Permanente (APPs) foram reduzidas nos topos de morros, montes, montanhas e serras (restringindo essas feições àqueles maiores de $100 \mathrm{~m}$, com inclinação de $25^{\circ}$ - artigo $4^{\circ}$ ). Nas margens dos cursos d'água as APPs passaram a ser computadas a partir do leito "regular", ao invés de utilizar o nível mais alto (artigo $4^{\circ}$ ), e apenas as nascentes perenes, e não mais as intermitentes foram protegidas (artigo $4^{\circ}$ ). Ainda mais, algumas categorias de áreas de preservação permanente passaram a depender de ato do poder público para ser consideradas protegidas, como os casos de áreas úmidas e várzeas (artigo $\left.6^{\circ}\right)$. A recuperação das áreas de preservação permanente desmatadas até 2008 passou a ser de acordo com o tamanho da propriedade, definido em módulos fiscais (Tabela 1).

Tabela 1 - Comparação entre a Área de Preservação Permanente a ser recuperada para desmatamentos anteriores a julho de 2008 e a ser mantida em áreas não desmatadas, de acordo com a Lei no 12.651, de 2012.

\begin{tabular}{|c|c|c|c|}
\hline Localização & Módulos Fiscais & Recomposição & Manutenção \\
\hline \multirow{4}{*}{$\begin{array}{c}\text { Margem dos cursos } \\
\text { d'água }\end{array}$} & $\leq 1$ & $5 \mathrm{~m}$ & \multirow{4}{*}{$\begin{array}{c}\text { Depende da largura do } \\
\text { curso d'água. De } 30 \mathrm{~m} \\
\text { a } 500 \mathrm{~m}\end{array}$} \\
\hline & $1 \leq 2$ & $8 \mathrm{~m}$ & \\
\hline & $2 \leq 4$ & $15 \mathrm{~m}$ & \\
\hline & $>4$ & $20 \mathrm{~m} \leq 100 \mathrm{~m}$ & \\
\hline Nascentes & Independe & $15 \mathrm{~m}$ & $50 \mathrm{~m}$ \\
\hline \multirow{4}{*}{$\begin{array}{c}\text { Lagos e lagoas } \\
\text { naturais }\end{array}$} & $\leq 1$ & $5 \mathrm{~m}$ & \multirow{4}{*}{$\begin{array}{l}\text { Zonas rurais } 100 \mathrm{~m} \text { ou } \\
50 \mathrm{~m}(\leq 20 \text { hectares }) \\
\text { zona urbana } 30 \mathrm{~m}\end{array}$} \\
\hline & $1 \leq 2$ & $8 \mathrm{~m}$ & \\
\hline & $2 \leq 4$ & $15 \mathrm{~m}$ & \\
\hline & $>4$ & $30 \mathrm{~m}$ & \\
\hline \multirow{2}{*}{ Veredas } & $\leq 4$ & $30 \mathrm{~m}$ & \multirow{2}{*}{$50 \mathrm{~m}$} \\
\hline & $>4$ & $50 \mathrm{~m}$ & \\
\hline
\end{tabular}


O tamanho do lote considerado "pequena propriedade" passou a vigorar de acordo com a Lei n ${ }^{\circ} 11.326$, saindo de 150 ha, no máximo, para até 440 ha, baseado no módulo fiscal, que varia de 5 a 110 ha, dependendo da região (INCRA, 1980). No caso dos conceitos de "utilidade pública" e de "interesse social", que servem para determinar as restrições à proteção das áreas de preservação permanente, foram incluídas instalações destinadas a eventos esportivos e foi criada mais uma categoria: "atividades eventuais ou de baixo impacto ambiental" (artigo $2^{\circ}$ ).

\section{CONTROVÉRSIAS DO CÓDIGO DE 2012 E O FUTURO DAS FLORESTAS BRASILEIRAS}

Todas essas alterações foram alvo de investigação e críticas pela comunidade científica. A começar pela justificativa de que era necessário alterar a lei para aumentar a produção. A ideia foi contestada por pesquisadores de diversas áreas, argumentando que o aumento tecnológico e melhores práticas agropecuárias poderiam resolver essa questão, sem a redução das áreas protegidas (BRANCALION; RODRIGUES, 2010; MARTINELLI et al., 2010; MICHALSKI et al., 2010). Outra problemática decorre do entendimento antagônico entre a conservação ambiental e a produção de alimentos, sendo a natureza vista pelos proponentes da reforma do Código como empecilho ao desenvolvimento (MARTINELLI et al., 2010; SAUER; FRANÇA, 2012). Críticos da reforma argumentaram que a redução da vegetação nativa pode não resultar em ganhos imediatos aos produtores (MARTINELLI, 2011) e ainda levar à direção oposta, significando risco à agricultura e insegurança alimentar devido à redução na produção (LEES; PERES, 2007; SAUER; FRANÇA, 2012; SBPC; ABC, 2012), advinda da perda de serviços ambientais, com prejuízo principalmente aos pequenos produtores (FONSECA; NUNES-SILVA, 2010; RIBEIRO; FREITAS, 2010; FONSECA et al., 2013; SOARES-FILHO et al., 2014).

A redução da reserva legal, no sentido de estipular o cômputo na junção com as áreas de preservação permanente é preocupante, já que são dois instrumentos com funções legais e biológicas distintas, que protegem espécies diferentes e, por isso, não se interpõem. Essa junção, bem como a recomposição florestal com o cultivo de espécies exóticas faz com que os instrumentos sejam descaracterizados e haja redução na biodiversidade (BENJAMIN, 2000; METZGER, 2010). Da mesma forma, a recomposição no nível de bioma pode atingir diretamente a diversidade biológica devido à distância física e às grandes lacunas geradas entre os ambientes protegidos (FREITAS, 2010; METZGER, 2010), e implica em dificultar ainda mais a fiscalização (FEARNSIDE, 2000). Para não perder 
a capacidade de representar as diferenças ecossistêmicas, é preciso garantir a proteção desde o nível regional até o nacional (FREITAS, 2010).

A possibilidade de redução da reserva legal para 50\% no bioma Amazônia tem valores próximos da capacidade mínima para a proteção da fauna, que é de 60\% de área florestada (METZGER, 2002), e deve ser agrupada entre propriedades formando fragmentos maiores. As reservas legais agrupadas perdem em diversidade de hábitats, porém são mais eficientes em evitar extinções. Para os demais biomas, a conservação $20 \%$ é tida como suficiente para garantir o uso pela fauna (METZGER, 2002, 2010).

Em relação às áreas de preservação permanente ao longo dos cursos d'água, a medida ideal varia de acordo com a sua função, localização, características geológicas e características da bacia hidrográfica. É uma medida de difícil determinação devido à complexidade dos ecossistemas e dos processos envolvidos (SILVA, 2003). Por isso, a largura que essas APPs deveriam ter é diferente para cada função desempenhada pela vegetação (Tabela 2). Em geral, todos os lotes são superiores aos $30 \mathrm{~m}$ mínimos exigidos, e muito superiores aos valores exigidos para a recomposição, de acordo com os módulos fiscais (Tabela 2).

Tabela 2 - Áreas de Preservação Permanente em zonas ripárias consideradas ideais segundo os diferentes critérios.

\begin{tabular}{|c|c|c|}
\hline $\begin{array}{c}\text { Faixa de } \\
\text { vegetação }\end{array}$ & Critério & Referências \\
\hline $5 \mathrm{~m}$ & Proteção de ravinas e córregos efêmeros & \multirow{2}{*}{ Bren, 1993} \\
\hline $80 \mathrm{~m}$ & Qualquer critério & \\
\hline $80 \mathrm{~m}$ & Proteção da composição florística em Cerrado & Silva Júnior, 2001 \\
\hline $52 \mathrm{~m}$ & Retenção de sedimentos & Sparovek et al., 2002 \\
\hline $\begin{array}{c}3,8 \mathrm{~m} \mathrm{a} \\
280 \mathrm{~m}\end{array}$ & $\begin{array}{l}\text { Estabilidade do talude; hábitat aquático e } \\
\text { de vida silvestre; retenção de nutrientes, } \\
\text { agrotóxicos e sedimentos; controle de } \\
\text { enchentes e da temperatura do rio. }\end{array}$ & Silva, 2003 \\
\hline $200 \mathrm{~m}$ & Hábitat para mamíferos e aves & Marco e Coelho, 2004 \\
\hline $60 \mathrm{~m}$ & Manutenção da avifauna & Tubeliset al., 2004 \\
\hline Mínimo $30 \mathrm{~m}$ & Proteção dos recursos hídricos & ANA, 2010 \\
\hline Mínimo $50 \mathrm{~m}$ & $\begin{array}{l}\text { Manutenção da biodiversidade como critério } \\
\text { mais restritivo }\end{array}$ & Metzger, 2010 \\
\hline
\end{tabular}

Fonte:

Ainda no caso da recomposição, o texto da lei descaracteriza o instrumento, dando uma conotação diferente do objetivo proposto pelas Áreas de Preservação Permanente, passando a ser baseada no tamanho da propriedade e no critério 
econômico, sendo desconsiderados o princípio de precaução (RIBEIRO; FREITAS, 2010), o conhecimento científico e os critérios ecológicos que motivaram a sua criação.

Além disso, a recomposição baseada no tamanho da propriedade gera insegurança jurídica, permite que nas duas margens de um mesmo rio os proprietários tenham que manter larguras de vegetação ripárias diferentes e dificulta a fiscalização, uma vez que o tamanho dos módulos fiscais pode vir a ser alterado (MPF, 2011). Ademais, se o interesse era privilegiar exclusivamente os pequenos proprietários com essa medida, há um equívoco, uma vez que a legislação não faz referência à pequena propriedade nos termos da agricultura familiar para essas situações (SOS FLORESTAS, 2011), e trata apenas em termos de módulo fiscal. Portanto, como no caso da isenção das reservas legais, a nova lei privilegia aqueles que desmataram de forma irregular e "pune" os proprietários que cumpriram a lei anterior (MPF, 2011).

A redução na medida das áreas de preservação permanente nos cursos d'água do nível maior para o leito regular ainda desprotege áreas importantes à conservação da biodiversidade, como as áreas úmidas e várzeas. A nova redação permite que sejam protegidas de acordo com interesses do poder público, porém, transforma o que era regra em exceção e dificulta o cumprimento de acordo sobre proteção de áreas úmidas da convenção Ramsar, da qual o Brasil é signatário. A inclusão e especificação desses dois termos na legislação não cumpre exatamente a sua função, que deveria ser de criar regras restritivas específicas à sua proteção (MPF, 2011; PIEDADE; GRAÇA, 2011a,b; PIEDADE et al., 2012).

Quando se trata da proteção da fauna, há perda de hábitats, risco de extinções e alterações na biodiversidade em diferentes grupos animais, como peixes (CASATTI, 2010), anfíbios (TOLEDO et al., 2010; SILVA et al., 2011), insetos (FONSECA; NUNES-SILVA, 2010; FREITAS, 2010), aves (DEVELEY; PONGILLUPI, 2010), répteis (MARQUES et al., 2010) e mamíferos (GALETTTI et al., 2010) devido a menores exigências em relação ao tamanho das reservas legais e de áreas de preservação permanente. Também são elencados riscos aos ecossistemas frágeis (RIBEIRO; FREITAS, 2010), às próprias atividades econômicas e à segurança social. Por exemplo, a redução da vegetação ripária irá tornar os rios mais susceptíveis a enchentes catastróficas (BREN, 1993; FEARNSIDE, 2010) e pode aumentar em até 300 vezes os custos de tratamento de água (TUNDISI; TUNDISI, 2010).

Para fazer valer todas as alternativas de recomposição e ter as multas anistiadas, os estados deverão criar os seus próprios programas de regularização ambiental e os proprietários, já devidamente registrados no cadastro ambiental 
rural, devem aderir ao programa do respectivo estado. Tanto o cadastro ambiental rural quanto o programa de regularização ambiental deverão ser implementados no período de um ano a partir da promulgação da lei, com previsão de prorrogação por mais um ano. Fica a expectativa de que o processo seja mais eficiente que a regularização da reserva legal exigida pelo Decreto $\mathrm{n}^{\circ}$ 6.514, que foi prorrogada por quatro anos e não foi concluída até a entrada em vigor do recente Código Florestal. Se o cadastro ambiental rural de fato funcionar, irá esclarecer muito sobre a condição das propriedades rurais, principalmente na região da floresta amazônica.

As alterações no atual Código Florestal foram realizadas sem preocupação com as questões científicas envolvidas (METZGER et al., 2010; TOLEDO et al.,2010; VIEIRA; BECKER, 2010; ARAÚJO; JURAS, 2012), com interesses voltados a um grupo específico relacionado ao agronegócio (TERRA DE DIREITOS, 2009; METZGER et al., 2010; ARAÚJO; JURAS, 2012; NAZARENO et al., 2012; TOLLEFSON, 2012), e as alterações explicitamente intentam legalizar as irregularidades, com o pacote de novos conceitos que regularizam os 42 milhões de hectares de passivo ambiental em reservas legais e os 43 milhões de hectares em áreas de preservação permanente deixados pelo Código de 1965 (SPAROVEK et al., 2011). Em extensão, essas mudanças podem ter consequências contrárias aos acordos internacionais sobre mudanças climáticas e proteção da biodiversidade e de ecossistemas frágeis com relevante interesse ecológico (MPF, 2011; PIEDADE; GRAÇA, 2011b; PIEDADE et al., 2012).

Mas mesmo com tantas fragilidades, a esperança é de que o "mais novo" Código Florestal Brasileiro seja respeitado, tenha melhor aplicabilidade e venha a atingir patamares de respeito à lei maiores que os atuais. Que seja munido de políticas de incentivo que facilitem a sua execução e que possa mudar a realidade ou a cultura de que no Brasil cumprir as leis para proteger as florestas é mais complicado do que não cumprir (HIRAKURI, 2003). Mas esse propósito talvez só seja alcançado com uma nova revisão da lei, visto que o principal legado trazido pelo atual Código é a premiação pela contravenção legal.

\section{CONCLUSÕES}

A legislação florestal brasileira surgiu primeiramente pelo puro interesse econômico e evoluiu atrelando a necessidade de conservação ambiental e produção de alimentos de forma mais equilibrada. O Código Florestal de 1965 criou mecanismos balizadores importantes à conservação das formações vegetais brasileiras e demais recursos naturais. Porém, a ineficiência na sua aplicação abriu brechas para a transição e criação de uma nova lei em 2012 que, além de fragilizar 
a proteção ambiental, pode incorrer nos mesmos erros da anterior. O Código Florestal de 2012 e a sua justificativa de concepção representam um incentivo à impunidade e desrespeito à legislação, com o intuito de resguardar interesses econômicos minoritários.

\section{REFERÊNCIAS}

AHRENS, S. O Código Florestal Brasileiro e o uso da terra: histórico, fundamentos e perspectivas (uma síntese introdutória). Revista de Direitos Difusos, v. 31, p. 81-102, 2005.

ALMEIDA, A. N. de; ANGELO, H.; SILVA, J. C. G. L. da; SOARES, P. R. C.; KANIESKI, M. R. Efetividade do aumento da área de Reserva Legal por meio de instrumento legal na taxa de desmatamento da Amazônia brasileira. Floresta e Ambiente, v. 20, n. 2, p. 143-148, 2013.

ANA-Agência Nacional de Águas. Nota Técnica nº45/2010. Brasília, DF: ANA, 2010. $12 \mathrm{p}$.

ANDRADE, J. T.; SILVA, J. A. Categorias de Florestas estabelecidas nos Códigos Florestais de 1934 e 1965. Floresta e Ambiente, v. 10, n. 2, p. 78-86, 2003.

ARAÚJO, S. M. V. G. de; JURAS, I. A. G. M. Debate sobre a nova lei florestal: análise dos textos aprovados na Câmara e no Senado. In: SOUZA, G.; JUCÁ, K.; WATHELY, M. (Eds.). Código Florestal e a Ciência: o que nossos legisladores ainda precisam saber. Brasília, DF: Comitê em defesa das florestas e do desenvolvimento sustentável, p. 105115, 2012.

BENJAMIN, A. H. V. A proteção das florestas brasileiras: ascensão e queda do Código Florestal. Revista de Direito Ambiental, v. 5, p. 21-37, 2000.

BONNET, B. R. P.; FERREIRA, L. G.; LOBO, F. C. Sistema de reserva legal extrapropriedade no Bioma Cerrado: uma análise preliminar no contexto da bacia hidrográfica. Revista Brasileira de Cartografia, v. 58, n. 2, p. 129-137, 2006.

BORGES, L. A. C.; REZENDE, J. L. P. de; PEREIRA, J. A. A.; JÚNIOR, L. M. C.; BARROS, D. A. de. Áreas de preservação permanente na legislação brasileira. Ciência Rural, v. 41, n. 7, p. 1202-1210, 2011.

BRANCALION, P. H. S.; RODRIGUES, R. R. Implicações do cumprimento do Código Florestal vigente na redução de áreas agrícolas: um estudo de caso da produção canavieira no estado de São Paulo. Biota Neotropica, v. 10, n. 4, p. 63-66, 2010.

BRASIL. 1934. Decreto n 23.793, de 23 de janeiro de 1934. Brasília, DF: PR, 1934.

BRASIL. 1965. Lei n 4.771, de 15 de setembro de 1965. Brasília, DF: PR, 1965.

BRASIL. 2012. Lei n 12.651, de 25 de maio de 2012. . Brasília, DF: PR, 2012.

BREDA, M.; SOUZA, M. F. R. de; SIQUEIRA, J. A reforma do Código Florestal: reflexão, inovações e perspectivas. Informativo STPC, v. 14, p. 15-18, 2011. 
BREN, L. J. Riparian zone, stream and floodplain issues: A review. Journal of Hydrology, v. 150 , p. $277-299,1993$.

CARVALHO, E. B. Legislação Florestal, território e modernização: o caso do Estado do Paraná 1907-1960. In. SIMPÓSIO NACIONAL DE HISTÓRIA, 24, 2007. São Leopoldo. Anais... São Leopoldo, 2007. 10p.

CASATTI L. Alterações no Código Florestal Brasileiro: impactos potenciais sobre a ictiofauna. Biota Neotropica, v. 10, n. 4, p. 31-34, 2010.

DELALIBERA, H. C.; NETO, P. H. W.; LOPES, A. R. C.; ROCHA, C. H. Alocação de reserva legal em propriedades rurais: do cartesiano ao holístico. Revista Brasileira de Engenharia Agrícola e Ambiental, v. 12, n. 3, p. 286-292, 2008.

DEVELEY, P. F.; PONGILLUPI, T. Impactos potenciais na avifauna decorrentes das alterações propostas para o Código Florestal Brasileiro. Biota Neotropica, v. 10, n. 4, p. 43-45, 2010.

ELLINGER, P.; BARRETO, P. Código Florestal: como sair do impasse? Belém: Imazon, 2011. Pará. 13 p.

FEARNSIDE, P. M. Código Florestal: O perigo de abrir brechas. Ciência Hoje, v. 28, n. 162, p. 62-63, 2000.

FEARNSIDE, P. M. Desmatamento na Amazônia: dinâmica, impactos e controle. Acta Amazonica, v. 36, n. 3, p. 395-400, 2006.

FEARNSIDE, P. M. The roles and movements of actors in the deforestation of Brazilian Amazonia. Ecology and Society, v. 13, n. 1, p. 23, 2008. Disponível em: < http://www. ecologyandsociety.org/ vol13/iss1/art23/>. Acesso em: 11 jul. 2013.

FEARNSIDE, P. M. Código Florestal: as perdas invisíveis. Ciência Hoje, v. 46, n. 273, p. 66-67, 2010.

FONSECA, M. G.; VALE, R. S. T. do; DANTAS, C. G.; PESAMOSCA, C.; AUGUSTO, C. C.; VILLAS-BÔAS, A. Redução do passivo ambiental em Áreas de Preservação Permanente em São José do Xingu (MT) em decorrência da revogação da Lei 4.771/65 (o Código Florestal Brasileiro). In. Simpósio Brasileiro de Sensoriamento Remoto, 15, 2013. Foz do Iguaçu. Anais... Foz do Iguaçu: INPE, p. 4845- 4852, 2013.

FONSECA, V. L. I.; NUNES-SILVA, P. As abelhas, os serviços ecossistêmicos e o Código Florestal Brasileiro. Biota Neotropica, v. 10, n. 4, p. 59-61, 2010.

FRANCO, J. L. A.; DRUMMOND, J. A. Wilderness and the Brazilian mind (II): the first Brazilian Conference on Nature Protection (Rio de Janeiro, 1934). Environmental History, v. 14, p. 82-102, 2009.

FREITAS, A. V. L. Impactos potenciais das mudanças propostas no Código Florestal Brasileiro sobre as borboletas. Biota Neotropica, v. 10, n. 4, p. 53-57, 2010.

GALETTI, M.; PARDINI, R.; DUARTE, J. M. B.; SILVA, V. M. F. da; ROSSI, A.; PERES, C. A. Mudanças no Código Florestal e seu impacto na ecologia e diversidade dos mamíferos no Brasil. Biota Neotropica, v. 10, n. 4, p. 47-52, 2010. 
HIRAKURI, S. R.Can law save the forest? Lessons from Finland and Brazil. Jakarta: Center for International Forestry Research, 2003. 120p.

IGARI, A. T.; PIVELLO, V. R. Crédito Rural e Código Florestal: irmãos como Caim e Abel? Ambiente e sociedade, v. 14, n. 1, p. 133-150, 2011.

INCRA-Instituto Nacional de Colonização e Reforma Agrária. Instrução Especial n ${ }^{\circ} 20$, de 28 de maio de 1980. Brasília, DF. INCRA, 1980.148 p.

LEES, A. C.; PERES, C. A. Conservation value of remnant riparian forest corridors of varying quality for Amazonian birds and mammals. Biodiversity and Conservation, v. 13, p. 1245-1255, 2007.

MARCO JR. P. de; COELHO, F. M. Services performed by the ecosystem: forest remnants influence agricultural cultures' pollination and production. Biodiversity and Conservation, v. 22, n. 2, p. 439-449, 2004.

MARQUES, O. A. V.; NOGUEIRA, C.; MARTINS, M.; SAWAYA, R. J. Impactos potenciais das mudanças propostas no Código Florestal Brasileiro sobre os répteis brasileiros. Biota Neotropica, v. 10, n. 4, p. 39-41, 2010.

MARTINELLI, L. A. Block changes to Brazil's Forest Code. Nature, v. 474, p. 579-579, 2011.

MARTINELLI, L. A.; JOLY, C. A.; NOBRE, C. A.; SPAROVEK, G. A falsa dicotomia entre a preservação da vegetação natural e a produção agropecuária. Biota Neotropica, v. 10, n. 4, p. 323-330, 2010.

MEDEIROS, R.; IRVING, M.; GARAY, I. A proteção da natureza no Brasil: evolução e conflitos de um modelo em construção. Revista de Desenvolvimento Econômico, v. 9, p. 83-93, 2004.

METZGER, J. P. Bases biológicas para a "Reserva Legal". Ciência Hoje, v. 31, n. 183, p. 48-49, 2002.

METZGER, J. P. O Código Florestal tem base científica? Natureza \& Conservação, v. 8, n. 1, p. 92-99, 2010.

METZGER, J. P; LEWINSOHN, T. M.;JOLY, C. A.; VERDADE, L. M.; MARTINELLI, L. A.; RODRIGUES, R. R. Brazilian law: Full speed in reverse? Science, v. 329, p. 276$277,2010$.

MICHALSKI, F.; NORRIS, D.; PERES, C. A. No return from biodiversity loss. Science, v. 329, p. 1282-1282, 2010.

MONTEIRO FILHO, A. Exposição de motivos. Série documentária $n^{\circ} 23$. Rio de Janeiro: Ministério da Agricultura/Serviço de informação Agrícola, 1962. 14p.

MPF-Ministério Público Federal. O novo Código Florestal e a atuação do Ministério Público Federal. $4^{a}$ Câmara de Coordenação e Revisão, GT Áreas de Preservação Permanente. Brasília, DF: MPF, 2011. 177 p. 
NAZARENO, A. G.; FERES, J. M.; CARVALHO, D. de; SEBBENN, A. M.; LOVEJOY, T. E.; LAURANCE, W. F. Serious new threat to Brazilians forests. Conservation Biology, v. 26, n. 1, p. 5-6, 2012.

PARANÁ. Lei no 706, de $1^{\circ}$ de abril de 1907. Disponível em: <http:/ / www.universoverde. com.br/ legislacao/estadual/parana/leprlei0706codflores.htm>. Acesso em: 11 jul. 2013.

PIEDADE, M. T. F.; GRAÇA, P. M. L. A. Código Florestal comentado. Manaus: Instituto Nacional de Pesquisas da Amazônia, 2011a. 36 p.

PIEDADE, M. T. F.; GRAÇA, P. M. L. A. O Código Florestal: contribuições do INPA para o diálogo. Manaus: Instituto Nacional de Pesquisas da Amazônia, 2011b. 15 p.

PIEDADE, M. T. F.; JUNK, W.J.; SOUSA JR., P.T. de; CUNHA, C. N. da; SCHÖNGART, J.; WITTMANN, F.; CANDOTTI, E.; GIRARD, P. As áreas úmidas no âmbito do Código Florestal Brasileiro. In: SOUZA, G.; JUCÁ, K.; WATHELY, M. (Eds.). Código Florestal e a Ciência: o que nossos legisladores ainda precisam saber. Brasília, DF: Comitê em Defesa das Florestas e do Desenvolvimento Sustentável, 2012. p. 9-17.

REBELO, A. Parecer do relator deputado federal Aldo Rebelo (PCdoB-SP) ao Projeto de Lei no 1876/99 e apensados. Brasília, DF: Câmara dos Deputados, 2010. 270 p.

RIBEIRO G. V. B. A origem histórica do conceito de área de preservação permanente no Brasil. Revista Thema, v. 1, n. 8, p. 1-13, 2011.

RIBEIRO, K. T.; FREITAS, L. Impactos potenciais das alterações no Código Florestal sobre a vegetação de campos rupestres e campos de altitude. Biota Neotropica, v. 10, n. 4, p. 239-246, 2010.

SAUER, S.; FRANÇA, S. C. Código Florestal, função socioambiental da terra e soberania alimentar. Caderno CRH, v. 25, n. 65, p. 285-307, 2012.

SBPC-Sociedade Brasileira para o Progresso da Ciência; ABC-Academia Brasileira de Ciências. O Código Florestal e a Ciência: contribuições para o diálogo. 2. ed. São Paulo: SBPC;ABC, 2012. 149 p.

SILVA JÚNIOR, M. C. da. Comparação entre matas de galeria no Distrito Federal e a efetividade do Código Florestal na proteção de sua biodiversidade arbórea. Acta Botânica Brasílica, v. 15, n. 1, p. 139-146, 2001.

SILVA, R. S. da; PRADO, V. H. M. do; ROSSA-FERES, D. C. Value of small forests fragments to amphibians. Science, v. 332, p. 1033-1033, 2011.

SILVA, R. V. da. Estimativa de largura de faixa vegetativa para zonas ripárias: uma revisão. In: SEMINÁRIO DE HIDROLOGIA FLORESTAL: ZONAS RIPÁRIAS, 1, 2003. Florianópolis, Anais... Florianópolis: UFSC, 2003. p. 74-86. Disponível em: <http:// produtordeagua.ana.gov.br/Portals/ 0/DocsDNN6/documentos/Largura_zonas_ riparias2003.pdf>. Avesso em: Acesso em: 11 jul. 2013.

SIQUEIRA, C. F. A.; NOGUEIRA, J. M. O novo Código Florestal e a Reserva Legal: do preservacionismo desumano ao conservacionismo politicamente correto. 20p. In: Encontro Brasileiro de Economia e Sociologia Rural - Encontro da Sociedade Brasileira de Economia e Sociologia Rural-SOBER, 42. 2004. Cuiabá. Anais... Brasília, DF: SOBER, 2004. 
SOARES-FILHO, B. S.; RAJÃO, R.; MACEDO, M.; CARNEIRO, A.; COSTA, W.; COE, M.; RODRIGUES, H.; ALENCAR, A. Cracking Brazil's forest code. Science, v. 344, p. 363-364, 2014.

SOS Florestas. Código Florestal: entenda o que está em jogo com a reforma da nossa legislação ambiental. Cartilha. 2011. 20p. Disponível em: < http://www.mosaicobocaina. org.br/noticias/259-noticias-ongs-lancam-cartilha-para-explicar-riscos-com-mudancasno-codigo-florestal>

SPAROVEK, G.; BARRETO, A.; KLUG, I.; PAPP, L.; LINO, J. A revisão do Código Florestal Brasileiro. Novos Estudos, v. 89, p. 111-135, 2011.

SPAROVEK, G.; BERNDES, G.; KLUG, I. L. F.; BARRETTO, A. G. O. P. Brazilian agriculture and environmental legislation: status and future challenges. Environmental Science \& Technology, v. 44, n. 16, p. 6046-6053, 2010.

SPAROVEK, G.; RANIERI, S. B. L.; GASSNER, A.; MARIA, I. C. D.; SCHNUG, E.; SANTOS, R. F. dos; JOUBERT, A. A conceptual framework for the definition of the optimal width of riparian forests. Agiculture, Ecosystems and Environment, v. 90, p. 169-175, 2002.

STICKLER, C. M.; NEPSTAD, D. C.; AZEVEDO, A. A.; MCGRATH, D. G. Defending public interests in private lands: compliance, costs and potential environmental consequences of the Brazilian Forest Code in Mato Grosso. Philosophical Transactions of the Royal Society of London, B Biological Sciences. v. 368, n. 1619, art. 20120160. p. 1-13., 2013.

TERRA DE DIREITOS. Mudanças na legislação ambiental e os reflexos na agricultura familiar camponesa e povos e comunidades tradicionais: subsídios técnicos e políticos para o debate. Curitiba, 2009. 26p.

TOLEDO, L. P.; CARVALHO-E-SILVA, S. P. de; SÁNCHEZ, C.; ALMEIDA, M. A. de; HADDAD, C. F. P. A revisão do Código Florestal Brasileiro: impactos negativos para a conservação dos anfíbios. Biota Neotropica, v. 10, n. 4, p. 35-38, 2010.

TOLLEFSON, J. Brazil set to cut forest protection. Nature, v. 485, p. 19-19, 2012.

TUBELIS, D. P.; COWLING, A.; DONELLY, C. Landscape supplementation in adjacent Savannas and its implications for the design of corridors for forest birds in the central Cerrado, Brazil. Biological Conservation, n. 118, p. 353-364, 2004.

TUNDISI, J. G.; TUNDISI, T. M. Impactos potenciais das alterações do Código Florestal Brasileiro nos recursos hídricos. Biota Neotropica, v. 10, n. 4, p. 67-75, 2010.

VIEIRA, I. C. G.; BECKER, B. K. A revisão do Código Florestal e o desenvolvimento do país. Ciência Hoje, v. 46 n. 274, p. 64-67, 2010. 